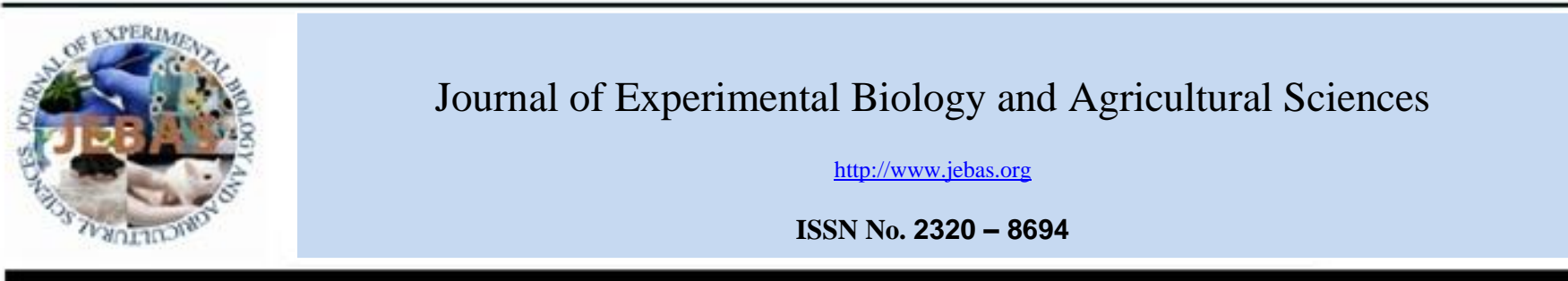

\title{
SELECTION AND IDENTIFICATION OF A NOVEL THERMOTOLERANT Kluyveromyces marxianus STRAIN FOR VALORIZATION OF LACTOSE WASTE INTO ETHANOL
}

\author{
B. H. Joshi ${ }^{*}$, R. M. Dhingani, R. V. Prasad \\ Department of Food Quality Assurance, College of Food Processing Technology and Bioenergy, Anand Agricultural University, Anand, Gujarat (INDIA) \\ Received - October 16, 2017; Revision - March 15, 2018; Accepted - May 15, 2018 \\ Available Online - June 20, 2018
}

DOI: http://dx.doi.org/10.18006/2018.6(3).482.489

\author{
KEYWORDS \\ Lactose waste \\ Valorization \\ Consolidated Bioprocessing \\ Fermentation \\ Ethanol yield
}

* Corresponding author

E-mail: bhavesh@aau.in (B. H. Joshi)

Peer review under responsibility of Journal of Experimental Biology and Agricultural Sciences.

Production and Hosting by Horizon Publisher India [HPI] (http://www.horizonpublisherindia.in/).

All rights reserved.

\begin{abstract}
Sustainable production of ethanol as alternative renewable fuels, there is a need for a yeast strain which can convert the non-food substrate into ethanol economically. Extensive screening program for such yeast for bioethanol production was attempted from the diverge ecosystem. That resulted into isolation of a yeast strain, designated strain ETDLT1, which was capable of ethanol fermentation using lactose as carbon source even at elevated temperatures. Beside this the strain is ethanol tolerant up to $12 \%$. The lactose fermentation performance of selected ETDLT1 strain was evaluated. It was found to produce 28 $\mathrm{g} / \mathrm{l}$ of ethanol with yield of $0.36 \%$. (p/s, g/g). In laboratory fermentation ETDLT1 strain found significant potential for its ability for bioconversion of dairy processing wastes rich in lactose into ethanol in single step fermentation. Therefore, it was further selected for thorough characterization. Results of characteristics confirm the ETDLT1 isolate as the strain of Kluyveromyces marxianus.
\end{abstract}

All the article published by Journal of Experimental Biology and Agricultural Sciences is licensed under a Creative Commons Attribution-NonCommercial 4.0 International License Based on a work at www.jebas.org.

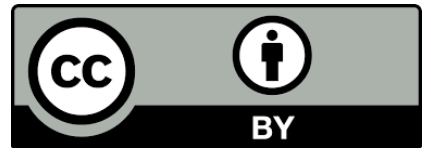




\section{Introduction}

Sustainable and economical production of ethanol or alternative renewable fuels are becoming increasingly important due to the limited supply of fossil fuels and the environmental consequences associated with their consumption (Balat, 2011; Binod et al., 2010). Present attention has been focused on development of alternative feedstock for its bioconversion into ethanol using potential microorganisms e.g., plant biomass or non-food waste, into useful compounds including ethanol, has already been recognized. Intensive research is being carried out to establish robust and economically feasible processes for production of bioethanol (Wyman, 1999). However, initial complex pretreatment of such substrates for its conversion into fermentable sugars is key problem need to be addressed by cost effective process. Carbohydrate rich waste generated by food industries could be serves as alternative feed stocks for its bioconversion using microorganisms into commercially important products.

About 165 million tons of whey production is estimated worldwide. Out of which, about $95 \%$ whey is contributed by cheese production. In India, chhana and paneer is major source of whey. Due to nutrientrich nature, the whey has been emerged as alternative feedstock for microbial fermentations (Liu et al., 2016). Cheese whey, the main dairy by-product, is increasingly recognized as a source of many bioactive valuable compounds. Nevertheless, the most abundant component in whey is lactose (ca. 5\% w/v), which represents a significant environmental problem. Technology is available to recover the protein from the whey, but, no adequate method is available for the utilization of whey lactose. Thus, it becomes necessitate to develop some strategy for valorization of whey lactose into marketable products. Due to the large lactose surplus generated, its conversion to bioethanol has long been considered as a possible solution for whey management (Guimaraes et al., 2010; Minakshi \& Shilpa, 2012).

The search of microorganism that efficiently ferments lactose has a high biotechnological interest, particularly for cheese whey management with simultaneous bioethanol production. Yeasts, particularly Saccharomyces spp., are the most common ethanol producers employed in industry (Edgardo et al., 2008). The fermentation of whey lactose to ethanol, particularly using yeasts, has been frequently referred in the literature, since at least the 1940s (Whittier, 1944; Rogosa et al., 1947; Webb \& Whittier, 1948). Although the yeasts that assimilate lactose aerobically are widespread, those that ferment lactose are rather rare (Fukuhara, 2006), including e.g. Kluyveromyces lactis, $K$. marxianus, and Candida pseudotropicalis. The conversions of the lactose in cheese whey or whey permeate into fuel ethanol represents an advantage of whey over food-related fermentation feed stocks, such as corn, for ethanol production. Although, the viability of such bioprocessing is largely depends on its cost economics.

Ethanol fermentation is affected by temperature rises during hot climates. In India, ambient temperature of $40^{\circ} \mathrm{C}$ and above is common in summer months. This requires cooling to maintain the temperature, which is not yet economically viable. However, the problem could be alleviated by using thermotolerant strains of yeast, which could capable to grow and produced ethanol at elevated temperatures. Other than thermotolerance, broad substrate utilization ability, higher saccharification rate, ethanol yieldand low energy requirement are the desirable traits for the successful exploitation of yeast for ethanol production (Dung et al., 2012; Kumar et al., 2013; Arora et al., 2015; Scully \& Orlygsson, 2015). Therefore, the selection of the yeast strain is very crucial for bioconversion of different feedstock into ethanol. Present work was carried out to select an efficient thermotolerant yeast strain for valorization of lactoseat elevated temperature into ethanol.

\section{Materials and Methods}

\subsection{Isolation and primary screening of yeast}

Yeast was isolated from the different habitats during screening program conducted for present study. Total of sixty seven samples were collected from food products as well as food industrial waste. The procured samples were used to isolate yeast using direct as well as enrichment method. Isolates obtained were screened out for its ability to produce ethanol, tolerance to elevated temperature and higher concentration of ethanol (Joshi et al., 2017).

\subsection{Secondary screening for $\beta$-galactosidase activity}

Secondary screening of the selected yeast isolates based on its ability to produce $\beta$-galactosidase enzyme was carried out. The yeast isolates were activated by inoculating single colony in yeast extract peptone dextrose broth. Then it was incubated at $35^{\circ} \mathrm{C}$ for $30 \mathrm{~h}$ using shaker (120 rpm). Each of these activated isolates was streaked on lactose agar plates and incubated at $35^{\circ} \mathrm{C}$ for $48-72 \mathrm{~h}$. Well grown colonies from lactose agar plate was inoculated in $2 \mathrm{ml}$ of yeast extract peptone lactose medium containing $0.5 \%$ yeast extract, $1 \%$ peptone, $8 \%$ lactose and $\mathrm{pH} 5.6$ and incubated at $35^{\circ} \mathrm{C}$ overnight using orbital shaking at $120 \mathrm{rpm}$. Once the optimal growth was obtained, it was used for quantitative estimation of $\beta$-galactocidase activity using ONPG as substrate (Gupte\&Nair, 2010). The unit activity of $\beta$ galactosidase enzyme was calculated using following formula:

$$
\text { Units of } \beta \text {-galactosidase activity }=\frac{1000 \times \mathrm{OD}_{420}}{\mathrm{~V} \times \mathrm{t} \times \mathrm{OD}_{600}}
$$

$\mathrm{V}=$ the volume of cells $(\mathrm{ml}) ; \mathrm{t}=$ the incubation time $(\mathrm{min})$ 
2.3 Evaluation of potential ETDLT1 strain for ethanol production from lactose

After screening and selection of thermotolerant and lactose fermentingyeast isolates, it was further evaluated for ethanol production using lactose as a sole source of carbon. Each isolated colony from lactose agar was inoculated in $100 \mathrm{ml}$ yeast extract peptone lactose medium as inoculum medium in $(250 \mathrm{ml})$ flask (Dhaliwal et al., 2011). Laboratory fermentation studies were conducted using this active culture. Twelve per cent inoculum was used for the fermentation. At an interval every $12 \mathrm{~h}$ the ethanol production and sugar consumption was studied during the fermentation. ETDLT1 strain was evaluated based on fermentation process efficiency and ethanol yield as described by Joshi et al. (2017).

\subsection{Characterization of selected yeast isolate}

Characterization of selected ETDLT1 isolate was carried out as described in The Yeast: a taxonomic study, $4^{\text {th }}$ ed (Kurtzman $\&$ Fell, 1998). The morphological, biochemical and cultural characterization was followed by molecular characterization of $18 \mathrm{~S}$ rDNA sequencing. DNA of ETDLT1 isolate was extracted and purified for its sequencing (Maniatis et al.,1982). By using universal forward (1F-5') and reverse primer (4R-5') purified DNA was amplified and sequenced (Machida \& Knowlton, 2012). Using BLAST tool of NCBI species level identification of the selected ETDLT1 isolate was carried out.

\section{Results and Discussion}

\subsection{Isolation and primary screening of yeast}

Extensive screening for the yeast with potential traits and capability to convert various cheaply available food processing waste or byproducts is attempted. This resulted into isolation of 165 isolates from 67 samples from the diverse ecosystem using direct isolation using YEPD as well as enrichment using YEPD supplemented with starch, cellulose, lactose. These isolates were studied independently for their ability to tolerate elevate temperature, ethanol tolerance and ethanol production ability.

Two main strategies for screening of yeast strain for bioethanol production were considered. The first one is based on traits of yeast that favors the process economics by improving the productivity. The second one was the ability of primary screened isolates for direct bioconversion of food processing waste in to ethanol. Primary screening was carried out based on thermotolerant, ethanol tolerance and ethanol productivity followed by secondary search for the potential of the selected isolate for direct conversion of alternative sustainable sources of food processing waste, that would otherwise be considered environmental pollutants in to ethanol economically (Xue et al., 2013; Stankus, 2014). There are several reports for the utilization of cheese whey as a substrate for bioethanol production at industrial scale (Guimaraes et al., 2010) but present search is for the strain of yeast which can convert the lactose based dairy waste into ethanol in a single step at elevated temperature with improved process economics. Total of 165 yeast obtained from different ecosystem were primarily screened out based on their ethanol fermentation ability in the laboratory experiment. Results of fermentation revealed ethanogenic potential of 43 isolates. During industrial ethanol production, yeasts are exposed to various environmental stresses such as high temperature and high sugar concentrations. Cellular micro molecules are seriously damaged under stress conditions, which leading to inhibition of cell growth and fermentation. To avoid lethal damage, bioethanol industry requires the utilization of yeasts capable of working with stresses. Stress-tolerant yeasts are thought to naturally wide spread in nature (Tofighi et al., 2014). These 43 ethanogenic isolates were selected for further evaluation for their thermotolerance. The results shows 18 ethanogenic isolates to have temperature tolerance at $40^{\circ} \mathrm{C}$ and above. Eighteen isolates so far selected showing ethanogenicity and thermotolerance were further studied for their ethanol tolerance. The results shows isolates ETB1T, ETB2T, ETDLT1, ETSBT1, ETGS1, ETMT2, ETJT1 and ETHT1 were found to tolerate ethanol concentration more than $10 \%$.Ambient temperatures in most sugar-cane producing areas necessitate the use of microorganisms which can grow and produce ethanol at temperatures above $40^{\circ} \mathrm{C}$ (Banat et al., 1992; Fleming et al., 1993; Barron et al., 1994). This is due to the energy savings achieved through the reduction of the expensive cooling and sterilization processes. Several reports revealed inhibitory effects and related problems in the fermentation of concentrated carbon, particularly slow fermentations and high residual sugar (Gawel \& Kosikowski, 1978; Janssens et al., 1983; Vienne \& von Stockar, 1985; Kamini \& Gunasekaran, 1987; Grubb \& Mawson, 1993; Dale et al., 1994; Silveira et al., 2005; Zafar et al., 2005; Ozmihci \& Kargi, 2007). Main cause of these problems is osmotic sensitivity and low ethanol tolerance (Janssens et al., 1983; Vienne \& von Stockar, 1985; Grubb \& Mawson, 1993; Zafar et al., 2005). The extent of such effects seems to be strain-dependent, although the fermentation conditions may as well play a key role in this regard (Guimaraes et al., 2010). Because the low lactose content in food waste such as whey $(4-5 \% \mathrm{v} / \mathrm{v})$, osmotic sensitivity is not much important for the conversion of whey lactose into ethanol. However whey based medium required to be supplemented by lactose or concentration of whey lactose by ultrafiltration and/or reverse osmosis processes/distillation. However the thermotolerance and ethanol tolerance of the yeast are significantly improve the process economics. So far collected ethanogenic thermotolerant and ethanol tolerant yeast isolates were further studied for their different biochemical potential for the conversion of cheaper substrates into ethanol with lower economics. 


\subsection{Secondary screening of selected yeast for $\beta$-galactosidase} activity

Valorization of lactose waste particularly the large amount of whey generated in cheese production remaining after the coagulation of milk and removal of casein is an aqueous by-product (Spalațelu, 2012). The main components of whey include lactose, protein, lipids and mineral matter, with lactose (4.5-5\%) being the major component (Kosikowski, 1979). Other components are protein, salts and vitamins present in minor amounts. Low concentration of these components makes their recovery uneconomical. Because of high organic contents dumping directly to environment causes serious contamination problem (Nahvi \& Moeini, 2004). The high percent of organic content in whey increases its biological and chemical oxygen demand; make it a cost intensive process (Marwaha \& Kennedy, 1988). The high lactose content in the whey can be valorized in to value added products by microbial fermentations (Sonawat et al., 1981). This kind of cheap substrate can be used to improve the economy of the process for the production of the ethanol using efficient strains of yeast which can beside ethanogenic, also able to split the lactose into fermentable sugar. For this conversion $\beta$ - galactosidase activity is very much desired. Considering this final screening of selected isolates was carried out based on ability to produce $\beta$ - galactosidase enzymes. Studies reveals out of these 8 isolates, ETDLT1, ETMT2, EHT1 and ETJT1 were found to show significant $\beta$ - galactosidase activity necessary for lactose utilization. Upon the quantification of $\beta$ galactosidase enzyme, isolate ETDLT1 was found to produce maximum of $72.2 \mathrm{IU} / \mathrm{ml}$. While other potential isolates ETMT2, ETHT2 and ETJT1 were found to produce 49.21, 41.07 and 36.51 $\mathrm{IU} / \mathrm{ml}$ respectively. Based on the results ETDL1 isolate was found to be superior among the selected isolates as producing highest $\beta$ galactosidase thus selected for further studies. Overall extensive screening program revealed $\beta$ - galactosidase productionpotential of ethanogenic strain ETDLT1 which is also thermotolerant as well as ethanol tolerant. ETDLT1 strain shown better prospects for the bioconversion of lactose containing food waste in to ethanol and therefore was selected for characterization for their identification and further evaluation of their ethanol production ability using lactose containing medium in shake flask studies.

3.3 Evaluation of potential ETDLT1 strain for ethanol production from lactose

Laboratory shake flask fermentation was carried out to evaluate suitability of selected isolate for the ethanol production using lactose as a substrate.ETDLT1strain found most potential candidate amongst all studied, for CPB of lactose containing medium at elevated temperature. The fermentation profile of studies is showed in Figure1. The studies shows production of $28 \mathrm{~g} / \mathrm{l}$ of ethanol with yield of 0.36 ( $\mathrm{Y}=\mathrm{p} / \mathrm{s}, \mathrm{g} / \mathrm{g}$ ) by the ETDLT1 strain. The ability to grow and to

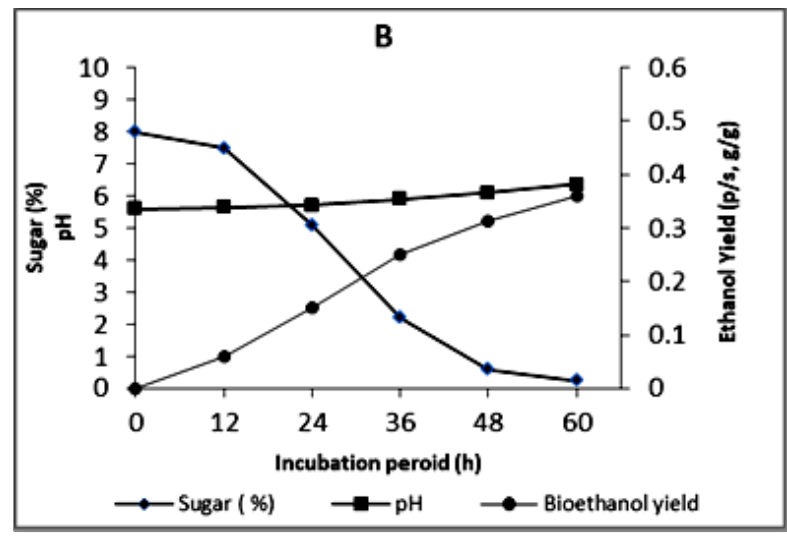

Figure 1 Fermentation kinetics of $K$. marxianus ETDLT1using lactose as carbon source for bioethanol production

produce ethanol from the $8 \%$ lactose containing medium is important as such medium can be formulated using dairy processing whey waste which other has limited uses which makes it difficult to dispose of. The ETDLT1 strain has shown inability to grow well anaerobically indicates that the fermentative sugar metabolism is inhibited by oxygen. Such characteristics are typical of yeast cells exhibiting the negative CRABTREE. Kluyveromyces spp., a Crabtree negative microorganism well known for its biotechnological ability (Etschmann et al., 2002), possesses a natural ability to excrete pectinolytic enzymes and produce different aroma compounds, like fruit esters, carboxylic acids and alcohols (Scharpf et al., 1986; Welsh et al., 1989; Fabre et al., 1998; Leclercq-Perlat et al., 2004). It can grow on a wide variety of substrates and at elevated temperatures when exposed to excess sugar, under this conditions it also has higher specific growth rates and a lower tendency to produce ethanol. In contrast, the onset of fermentation in Crabtree-negative $K$. marxianus cells is not dependent on the sugar concentration, but is regulated by a decrease in oxygen levels (van Urk et al., 1990; Verudyn et al., 1992). The $K$. marxianus strain MTCC 1288 from crude cheese whey containing $35 \mathrm{~g} \mathrm{~L}^{-1}$ of lactose at $34^{\circ} \mathrm{C}$ and $\mathrm{pH}$ maintained at 4.5 produced $2.10 \mathrm{~g} \mathrm{~L}^{-1}$ of ethanol and $8.9 \mathrm{~g} \mathrm{~L}^{-1}$ of cell mass (Zafar \& Owais, 2006). The ethanol production from medium containing $50 \mathrm{~g}$ $\mathrm{L}^{-1}$ of lactose by the same strain was $3.98 \mathrm{~g} \mathrm{~L}^{-1}$ and cell mass reached $10.34 \mathrm{~g} \mathrm{~L}^{-1}$, in the same temperature and $\mathrm{pH}$ conditions (Zafar et al., 2005). Another studies reported ethanol concentrations of ca. $22 \mathrm{~g} \mathrm{~L}^{-1}$ were found from whey containing ca. $44 \mathrm{~g} \mathrm{~L}^{-1}$ lactose at elevated temperature (Sansonetti et al., 2011). Liu et al. (2016) reported a high titerof $41 \mathrm{~g} / \mathrm{L}$ ethanol with the yield of $70 \%$ of the theoreticalmaximum by using a low-cost medium containing whey permeate as carbon source and corn steep liquor hydrolysate as nitrogen source in combination with a fed-batch strategy.Considering these studies, selected $K$. marxianusETDLT1strain reveals significant attributes for bioconversion of whey based waste of the dairy industries which is otherwise difficult to manage, into ethanol in 
single step fermentation. Looking to its prospects,it was selected for studiesto characterize for identification.

\subsection{Characterization of selected yeast isolate}

\subsubsection{Morphological characterization}

Morphological characteristics of isolate ETDLT1 were studied. The morphological features are shown in Figure 2 A and summarized in Table 1. The size of ETDLT1isolate was 5 to $12 \mu \mathrm{m}$ in length and 0.8 to $4 \mu \mathrm{m}$ in breadth. The cells normally occurred mainly in small clusters or occasionally singly.

\subsubsection{Cultural characterization}

The colony of ETDLT1 isolate iswhitish creamy in color, large in size, opaque, butryous in texture with raised elevation (Figure2 B).The cultural characteristics are shown in Table 1.

\subsubsection{Biochemical characterization}

Biochemical properties were determined for selected ETDLT1 isolate. The strain was found to utilise D-glucose, D-galactose, D-reffinose, Lactose and D-sucrose. Negative assimilations and fermentations were observed for maltose, melibiose, reffinose, inositol and trehalose. It is capable of utilising L-lysine but nitrate, and urea could not be used as nitrogen source. Vigorous growth was observed at $35^{\circ} \mathrm{C}$.

\subsubsection{Molecular Characterization of selected isolate}

ETDLT1 has shown $99 \%$ homology with the K. marxianus using online BLAST tool of NCBI. It reveals that ETDLT1 isolate is novel strain of $K$. marxianus yet been not reported in public domain. Further phylogenetic analysis of $K$. marxianus ETDLT1 with the other available sequenced genotype is shown below in the form of tree dendogram (Figure 3). Upon submission of sequin generated file to Gene bank KU173546 accession number is assigned to this newly isolated and selected strain of $K$. marxianus.

\section{Conclusion}

Valorization of lactose waste into ethanol is an interesting option for cheese wastewater management. Among these value-added products, ethanol has been recognized as a strategic product considering the rising costs of fossil fuels and greenhouse gas emission. Present extensive screening reveled thermotolerant strain of $K$. marxianus with potential to produce ethanol at 35 and $40^{\circ} \mathrm{C}$. The studies revealed this newly isolated strain of K. marxianus as a potential
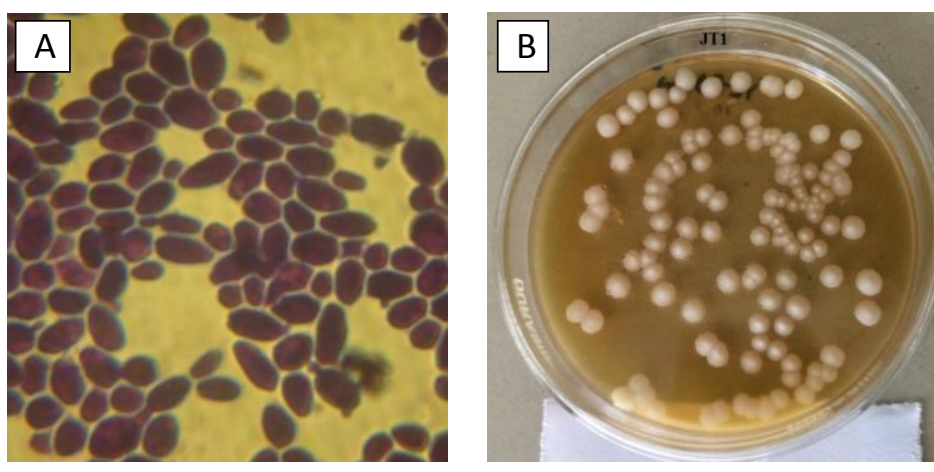

Figure 2A Morphological and B. Cultural characteristics of selected ETDLT1 isolate

Table 1 Characterization of selected ETDLT1 isolate

\section{Morphological characteristics}

\begin{tabular}{|ll|}
\hline Size & Large \\
\hline Shape & Elongated \\
\hline Arrangement & Single or cluster \\
\hline Cultural characteristics & \\
\hline Size & Large \\
\hline Shape & Round \\
\hline Margin & Entire \\
\hline Texture & Butryous \\
\hline Elevation & Raised \\
\hline Opacity & Opaque \\
\hline Colour & Whitish Creamy \\
\hline Biochemical characteristics
\end{tabular}

Biochemical characteristics

Assimilation of Carbon;

Glucose

Galactose

Maltose

Melibiose

Trehalose

Mannose

Raffinose

Sucrose

Lactose

Starch

Inisitol

\section{Assimilation of Nitrogen;}

Peptone

Yeast Extract

Ammonium Sulphate

Asparagine

Nitrate

L-lysine

Urea

+positive; -negative 


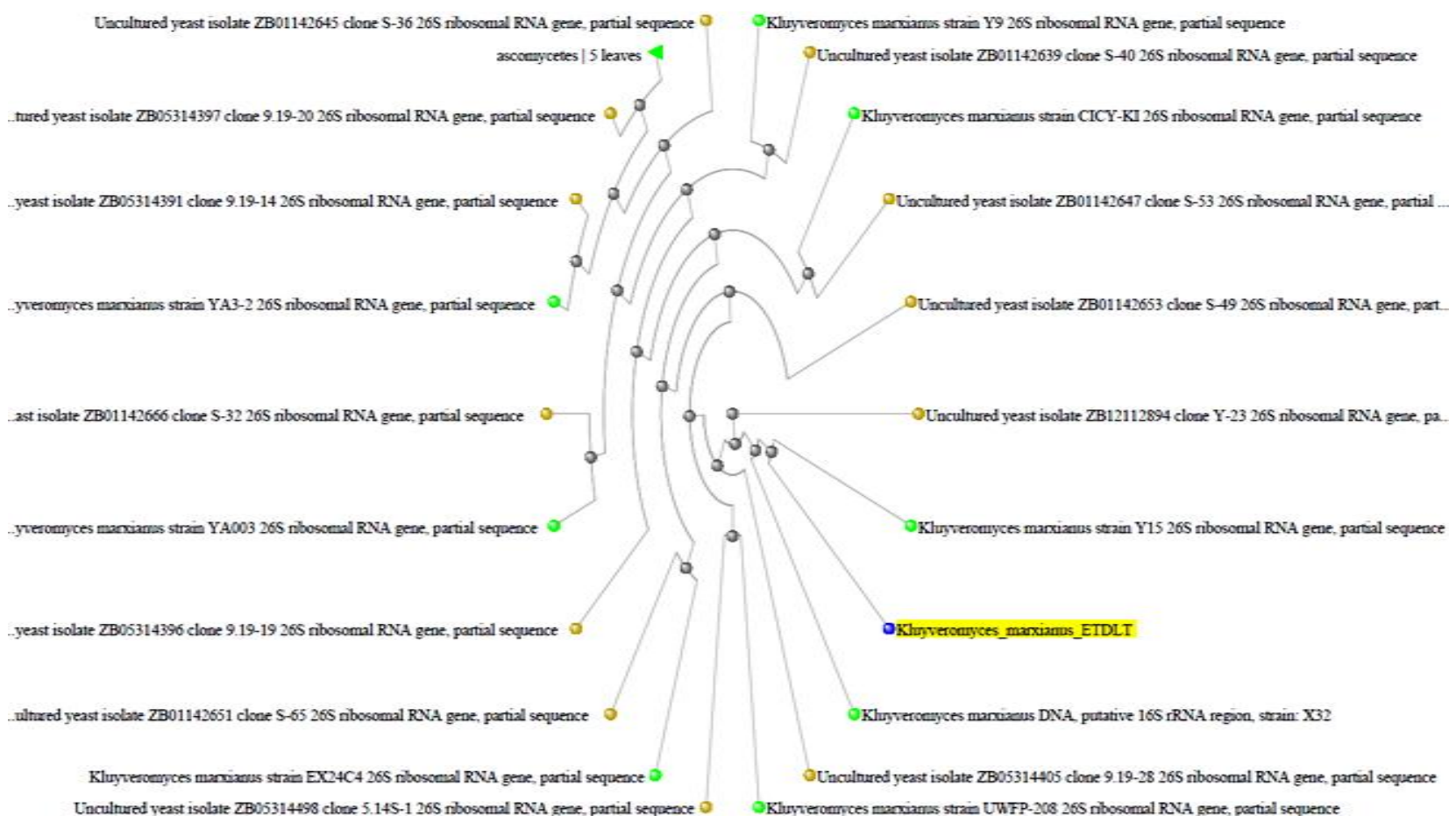

Figure 3 Distance tree of query sequence for K. marxianus ETDLT1 with available reference sequence in circular lay out form.

candidate to develop a cost-effective bioconversion process that can turn waste products from the dairy industry (whey) into value-added ethanol which has immediate potential for commercialization.

\section{Conflict of Interest}

Authors would hereby like to declare that there is no conflict of interests that could possibly arise.

\section{References}

Arora R, Behera S, Kumar S (2015) Bioprospecting thermophilic/thermotolerant microbes for production of lignocellulosic ethanol: a future perspective. Renewable and Sustainable Energy Reviews 51: 699-717.

Balat M (2011) Production of bioethanol from lignocellulosic materials via the biochemical pathway: A review. Energy Conversion and Management 52:858-875.

Banat IM, Nigam P, Marchant R (1992) The isolation of thermotolerant fermentativeyeasts capable of growth at $52^{\circ} \mathrm{C}$ and ethanol production at $45^{\circ} \mathrm{C}$ and $50^{\circ} \mathrm{C}$. World Journal of Microbiology and Biotechnology 8: 259-263.
Barron N, Marchant R, Mchale L, Mchale AP (1994) Growth of a thermotolerant ethanol-producing strain of Kluyveromyces murxianuson cellobiose media. Biotechnology Letters 16: 625-630.

Binod P, Sindhu R, Singhania RR, Vikram S, Devi L, Nagalakshmi S, Kurien N, Sukumaran RK, Pandey A (2010) Bioethanol production from rice straw: An overview. Bioresource Technology 101:4767-4774.

Dale MC, Eagger A, Okos MR (1994) Osmotic inhibition of free and immobilized Kluyveromyces marxianus anaerobic growth and ethanol productivity in whey permeate concentrate. Process Biochemistry 29:535-544.

Dhaliwal SS, Oberoi HS, Sandhu SK, Nanda D, Kumar D, Uppal SK (2011) Enhanced ethanol production from sugarcane juice by galactose adaptation of a newly isolated thermotolerant strain of Pichia kudriavzevii. Bioresource Technology 102 : 5968-5975.

Dung NTP, Thanonkeo P, Phong HX (2012) Screening useful isolated yeasts for ethanol fermentation at high temperature. International Journal of Applied Science and Technology 2: 65-71.

Edgardo A, Carolina P, Manuel R, Juanita F, Baeza J (2008) Selection of thermotolerant yeast strains Saccharomyces cerevisiae for bioethanol production. Enzyme and Microbial Technology 43 : 120-123. 
Etschmann MMW, Buemke W, Sell D, Schrader J (2002) Biotechnogical production of 2-phenyethanol. Applied Microbiology and Biotechnology 99: 1-8.

Fabre CE, Banc PJ, Goma G (1998) Production of 2-phenyethyl alcohol by Kluyveromyces marxianus. Biotechnology Progress 14 : 270-274.

Fleming M, Barron L, Mchale L, Marchant R, Mchale AP (1993) Studies on the growth of a thermotolerant yeast strain, Kluyveromyces marxianus IMB3, on sucrose containing media. Biotechnology Letters 15: 1195-1 198.

Fukuhara H (2006) Kluyveromyces lactis - a retrospective. FEMS Yeast Research 6:323-324.

Gawel J, Kosikowski FV (1978) Improving alcohol fermentation in concentrated ultrafiltration permeates of cottage cheese whey. Journal of Food Science 43:1717-1719.

Grubb CF, Mawson AJ (1993) Effects of elevated solute concentrations on the fermentation of lactose by Kluyveromyces marxianus Y-113. Biotechnology Letters 15:621-626.

Guimaraes MRP, Teixeira JA, Domingues L (2010) Fermentation of lactose to bioethanol by yeasts as part of integrated solutions for the valorisation of cheeses whey. Biotechnology Advances 28: 375-385.

Gupte AM, Nair JS (2010) $\beta$-galactosidase production and ethanol fermentation from whey using Kluyveromyces marxianus NCIM 3551. Journal of Scientific \& Industrial Research 69: 855-859.

Janssens JH, Burris N, Woodward A, Bailey RB (1983) Lipidenhanced ethanol production by Kluyveromyces fragilis. Applied and Environmental Microbiology 45:598-602.

Joshi BH, Dhingani RM, Prasad RV (2017) Selection and identification of a newly isolated thermotolerant and amylolytic Saccharomyces cerevisiae strain for ethanol production. Current Journal of Applied Science and Technology 24: 1-10.

Kamini NR, Gunasekaran P (1987) Simultaneous ethanol production from lactose by Kluyveromyces fragilis and Zymomonas mobilis. Current Microbiology 16:153-7.

Kosikowski FV(1979) Whey utilization and whey products, Journal of Dairy Science 62: 1149-1160.

Kumar S, Dheeran P, Singh SP, Mishra IM, Adhikari DK (2013) Cooling system economy in ethanol production using thermotolerant yeast Kluyveromyces sp. IIPE453. American Journal of Microbiological Research 1: 39-44.
Kurtzman CP, Fell JW (1998) The Yeasts, a Taxonomic Study, $4^{\text {th }}$ Ed., Elsevier, Amsterdam, The Netherlands. Pp. 77-102.

Leclercq-Perlat MN, Corrieu G, Spinnler HE (2004) Comparison of volatile compounds produced in model cheese medium deacidified by Debaryomyces hansenii and Kluyveromyces marxianus. Journal of Dairy Science 87: 1545-1550.

Liu J, Dantoft SH, Würtz A, Jensen PR, Solem C (2016) A novel cell factory for efficient production of ethanol from dairy waste. Biotechnology for Biofuels 9: 33.

Machida J, Knowlton N (2012) PCR Primers for metazoan nuclear $18 \mathrm{~S}$ and 28S ribosomal DNA sequences. PLOS One 7:1-11.

Maniatis T, Fritsch EF, Sambrook J (1982) Molecular Cloning: a Laboratory Manual.Cold Spring Harbor Laboratory, USA.

Marwaha SS, Kennedy JF (1988) Review: whey-pollution problem and potential utilization. International Journal of Food Science and Technology 23: 323-336.

Minakshi D, Shilpa V (2012) Comparative analysis of bioethanol production from whey by different strains of immobilized thermotolerant yeast. International Journal Scientific Research Public 2: $1-5$.

Nahvi I, Moeini H (2004) Isolation and identification of yeast strains with high beta-galactosidase activity from dairy products. Biotechnology 3: 35-40

Ozmihci S, Kargi F (2007) Effects of feed sugar concentration on continuous ethanol fermentation of cheese whey powder solution (CWP). Enzyme and Microbial Technology 41:876-880.

Rogosa M, Browne HH, Whittier EO (1947) Ethyl alcohol from whey. Journal of Dairy Science 30:263-269.

Sansonetti S, Hobley TJ, Calabro V, Villadsen J, Sina G (2011) A biochemically structured model for ethanol fermentation by Kluyveromyces marxianus: A batch fermentation and kinetic study. Bioresource Technology 102(16): 7513-7520.

Scharpf LG, Seitz EW, Morris JA, Farbood MI (1986) Generation of flavor and odor compounds through fermentation processes. In; Parliament TH, Croteau R (Eds). Biogeneration of Aroma, Vol 317, American Chemical Society: Washington, DC; 323-346.

Scully SM, Orlygsson J (2015) Recent advances in second generation ethanol production by thermophilic bacteria. Bioenergies 8: 1-30.

Silveira WB, Passos F, Mantovani HC, Passos FML (2005) Ethanol production from cheese whey permeate by Kluyveromyces marxianus UFV-3: a flux analysis of oxido-reductive metabolism as a function of 
lactose concentration and oxygen levels. Enzyme and Microbial Technology 36:930-936.

Sonawat HM, Agrawal A, Dutta SM (1981) Production of $\beta$ galactosidase from Kluyveromyces fragilis grown on whey. Folia Microbiologica 26: 370-376.

Spalațelu C (2012) Biotechnological valorisation of whey. Innovative Romanian Food Biotechnology 10: 1-8.

Stankus T (2014) Reviews of science for science librarians: microbes that make biofuels and work within fuel cells. Science \& Technology Libraries 33: 71-88.

Tofighi A, Assadi MM, Asadirad MHA, Karizi SZ (2014) Bioethanol production by a novel autochthonous thermo-tolerant yeast isolated from wastewater. Journal of Environmental Health Science \& Engineering 12: 1-6.

Van Urk H, Voll WSL, Scheffers WA, van Dijken JP (1990) Transient-state analyses of metabolic fluxes in Crabtree-positive and Crabtree-negative yeasts. Applied and Environmental Microbiology 56: $281-287$.

Verudyn C, Postma E, Scheffers WA, van Dijken JP (1992) Effect of benzoic acid on metabolic fluxes in yeasts: a continuous culture study on the regulation of respiration and alcoholic fermentation. Yeast 8: 501-517.

Vienne P, von Stockar U (1985) An investigation of ethanol inhibition and other limitations occurring during the fermentation of concentrated whey permeate by Kluyveromyces fragilis. Biotechnology Letters 7:521-526.

Webb BH, Whittier EO (1948) The utilization of whey: a review. Journal of Dairy Science 31:139-64.

Welsh FW, Murray WD, Williams RE (1989) Microbiological and enzymatic production of flavor and fragrance chemicals. Critical Reviews in Biotechnology 9: 105-169.

Whittier EO (1944) Lactose and its utilization: a review. Journal of Dairy Science 7:505-37.

Wyman CE (1999) BIOMASS ETHANOL: Technical Progress, Opportunities, and Commercial Challenges. Annual Review of Energy and the Environment 24:189-226. DOI: https://doi.org/10.1146/annurev.energy.24.1.189.

Xue C, Zhao X, Liu C, Chen L, Bai F (2013) Prospective and development of butanol as an advanced biofuel. Biotechnology Advances 31: 1575-84.

Zafar S, Owais M, Salleemuddin M, Husain S (2005) Batch kinetics and modelling of ethanolic fermentation of whey. International Journal of Food Science \& Technology 40:597-604.

Zafar S, Owais M (2006) Ethanol production from crude whey by Kluyveromyces marxianus. Biochemical Engineering Journal 27: 295-298.

Journal of Experimental Biology and Agricultural Sciences http://www.jebas.org 